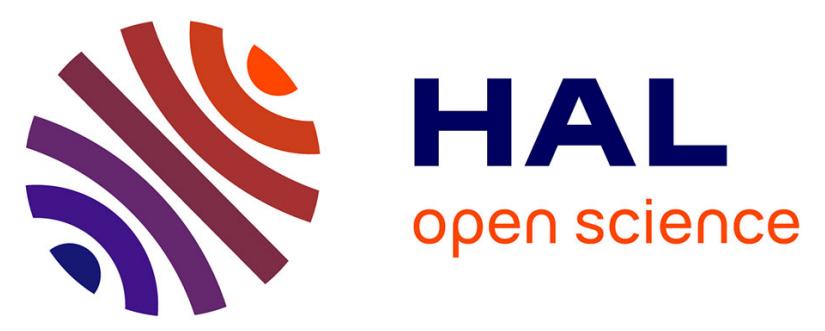

\title{
Health care in and outside a DMP for type 2 diabetes mellitus in Germany-results of an insurance customer survey focussing on differences in general education status
}

Thomas Elkeles, Wolf Kirschner, Christian Graf, Petra Kellermann-Mühlhoff

\section{To cite this version:}

Thomas Elkeles, Wolf Kirschner, Christian Graf, Petra Kellermann-Mühlhoff. Health care in and outside a DMP for type 2 diabetes mellitus in Germany-results of an insurance customer survey focussing on differences in general education status. Journal of Public Health, 2008, 17 (3), pp.205216. 10.1007/s10389-008-0234-5 . hal-00535267

\section{HAL Id: hal-00535267 https://hal.science/hal-00535267}

Submitted on 11 Nov 2010

HAL is a multi-disciplinary open access archive for the deposit and dissemination of scientific research documents, whether they are published or not. The documents may come from teaching and research institutions in France or abroad, or from public or private research centers.
L'archive ouverte pluridisciplinaire HAL, est destinée au dépôt et à la diffusion de documents scientifiques de niveau recherche, publiés ou non, émanant des établissements d'enseignement et de recherche français ou étrangers, des laboratoires publics ou privés. 


\title{
Health care in and outside a DMP for type 2 diabetes mellitus in Germany-results of an insurance customer survey focussing on differences in general education status
}

\author{
Thomas Elkeles • Wolf Kirschner • Christian Graf • \\ Petra Kellermann-Mühlhoff
}

Received: 20 May 2008 / Accepted: 10 November 2008 / Published online: 23 December 2008

(C) Springer-Verlag 2008

\begin{abstract}
Aim The Disease Management Programmes (DMPs) introduced in Germany since 2003 are intended to improve health care for the chronically ill. Whether they do this is currently being investigated in various evaluation settings. In order to assess possible changes in the process quality from the point of view of patients, the BARMER health insurance company conducted a national postal survey in Germany in 2007 of its customers with diabetes mellitus type 2 in order to compare programme participants and non-participants. This evaluation is a sub-analysis intended to clarify whether the utilisation, acceptability and perceived benefits of the programme differ as a result of educational status.

Subjects and Methods A nationally representative random sample was drawn from BARMER insurance customers with type 2 diabetes, aged 45-79 years. Questionnaires were evaluated from $38.5 \%$ of the sample (DMP-participant respondents: $n=2,158$; non-participant respondents: $n=$ 2,182).

Results A lower educational status was related among other things with increased morbidity, a poorer level of informa-
\end{abstract}

T. Elkeles $(\bowtie)$

Department of Health, Nursing, Management,

University of Applied Sciences Neubrandenburg,

Post Box 1101 21, 17041 Neubrandenburg, Germany

e-mail: elkeles@hs-nb.de

W. Kirschner

Research, Consulting Service + Evaluation $(\mathrm{FB}+\mathrm{E})$,

Berlin, Germany

C. Graf $\cdot$ P. Kellermann-Mühlhoff

BARMER Health Insurance,

Wuppertal, Germany tion and also a less well-developed "preventive attitude" to the disease. The finding that $49 \%$ of participants had a higher school qualification compared with $45 \%$ of nonparticipants, although significant, is less pronounced than the differences found between DMP participants and nonparticipants for other values analysed. A social influence could be found concerning the differences in treatment provided within the programme. A multivariate analysis shows that both the participation in the programme and higher levels of education have independent positive effects on the satisfaction with health status, with the effect of programme participation being stronger.

Conclusions It can be assumed that the clear differences established between the groups of DMP participants and non-participants can in no way be explained solely by the comparatively small difference related to school education. Patients obviously appreciate the fact that the health personnel and the insurance company are paying increased interest to their disease, and this is true to an increased degree for participants with only basic schooling. Although overall this group is significantly under-represented among the participants, they reported to an increased degree that they were profiting from the programme.

Keywords Disease management programme $\cdot$ Diabetes mellitus $\cdot$ Evaluation $\cdot$ Demands on doctors $\cdot$ Doctor-patient relationship · Coping $\cdot$ Social status $\cdot$ Educational level

\section{Introduction}

Disease Management Programmes (DMPs) were introduced as one of the new instruments for the integration of health care structures (Saltman and Otter 1995; Todd and Nash 1997; Veeder and Peebles-Wilkins 2001). The statutory 
health insurance funds (SHIs) receive additional compensation if their chronically ill customers enrol in structured care programmes, as an economic incentive to encourage both doctors and the statutory health insurance funds to improve the quality of care. The programmes are intersectoral, with evidence-based guidelines (Busse 2004; Graft 2006).

Currently, some 4 million customers of insurance companies in Germany are participating in a DMP for diabetes mellitus type 1 and type 2, coronary heart disease, breast cancer, asthma or COPD. Of these participants, more than 2.5 million are enrolled in the DMP for diabetes mellitus type 2.

In Germany there were reservations from the start about whether the experience in other countries with DMPs (cf. e.g. Robinson and Steiner 1998; Weingarten et al. 2002; Selby et al. 2003; Knight et al. 2005) would be transferable to the German health care system. Other concerns were directed less towards the programme itself and more against its integration in the system of risk structure compensation, and the incentives associated with this (cf. e.g. SVR 2007). Doubts were raised that the programme would be able to reach the right patient target groups (cf. Lippmann-Grob et al. 2003; Häussler et al. 2005; Dunkelberg et al. 2006).

There are also reasons to be sceptical about whether structural problems concerning the care of the chronically ill can be resolved for individual disease groups in isolation. In the positive case, that would at least mean that over a realistic period it was possible to modify in the intended way patterns of behaviour that have grown over many years both on the part of the health care providers and on the part of patients. We also include here the alteration of doctor-patient relationship and an activation of the patient role in the sense of 'shared decision making' (cf. Scheibler and Pfaff 2004; Faller 2006).

Previously published results from the so-called quality reports of the contractual partners in Germany at the federal state level for the DMP for diabetes mellitus type 2 (e.g. Altenhofen et al. 2006) do not provide a conclusive picture. Within the framework of the legally required evaluation, it is obligatory to conduct additional surveys of insurance customers, but these are restricted to studying the progress of the health-related quality of life without including a control group, as would be necessary for methodological reasons (cf. Gerlach et al. 2003; Morfeld and Koch 2005; Wegscheider et al. 2006).

In order to be able to investigate a possible change in the process quality from the point of view of the patients, the BARMER health insurance company commissioned a comparative national survey of its customers with diabetes mellitus type 2 in 2007 (programme participants and nonparticipants). The evaluation-commissioned by BARMERwas carried out by the Neubrandenburg University of Applied Sciences in cooperation with FB+E Institute.
Before the national survey, a regional survey was carried out of BARMER customers to determine preferences, motives and evaluations of participants in the DMP for diabetes mellitus type 2 (Elkeles et al. 2007). Among other things, this gave indications of:

- Participant interest in improved quality of care and a more active patient role,

- A doubling of the proportion of those visiting a specialist in diabetology compared with the period before enrolling in the DMP,

- Improvements in the evaluation of the quality of care and the state of health and

- Slight social selection processes.

Since the group reporting the most benefits was already relatively well informed about their own disease, it was not completely possible to discount critical comments such as those advanced by Eller et al. (2005) that these health programmes may involve social selection processes similar to those encountered in many other health programmes. Against the background of the general results of the BARMER insurance survey in 2007 (Elkeles et al. 2008), this contribution therefore concentrates on the social influence, measured by the level of school education as indicator, on the care received for diabetes mellitus and on the care in the DMP itself.

The main findings, comparing participants and nonparticipants in the BARMER diabetics survey of 2007 are (Elkeles et al. 2008):

- Some $57 \%$ of respondents were totally or very satisfied with the care their doctor provided for diabetes, the participants significantly more so with $61.1 \%$ compared to $52.6 \%$ for non-participants. Only about $6 \%$ of respondents were less satisfied or dissatisfied-with no significant difference between the groups.

- More DMP participants (80.6\%) assess their level of information about the causes and consequences of diabetes as good to very good, compared with $69.6 \%$ of non-participants.

- The doctor-patient relationship was mostly viewed positively. In all items, DMP participants were significantly more often positive than non-participants, so significantly more DMP participants (88.2\%) agreed with the statement "My doctor involves me in the decisions" than non-participants $(80.6 \%)$. Also the statements about the behaviour of practice nurses showed a significantly better evaluation by DMP participants.

- More DMP participants than non-participants were receiving treatment mainly from a diabetology practice ( $29.2 \%$ vs. $15.2 \%$, highly significant). Doctors arranged therapy targets more frequently with DMP participants 
(84.9\% vs. $70.8 \%$, highly significant). In the case of $\mathrm{HBA}_{1 \mathrm{c}}$ values, $72.6 \%$ of DMP participants were set a target, significantly more than non-participants (57.2\%).

- Non-DMP participants had on average 1.95 contacts with doctors each quarter compared to DMP participants who had 1.78 contacts. Of the participants, some $65 \%$ went only once per quarter for the check-up investigation (non-participants: $58 \%$ ). But $21 \%$ of the non-participants reported contacting the doctor's office three times or more per quarter (participants: 17\%). The overall contact frequency of DMP participants was lower, even though these patients were more severely ill and had higher co-morbidity.

- $\quad$ For DMP participants, $83.8 \%$ had their feet inspected, a highly significantly larger proportion than for nonparticipants $(63.6 \%)$; also a higher proportion had had an inspection in the year of the survey $(61.7 \%$ and $44.1 \%$, respectively).

- Regular eye inspections were carried out on $91 \%$ of all respondents, which is a higher percentage than for foot inspections. Eye inspections were also more frequent among DMP participants (96.2\%) than among nonparticipants $(85.3 \%)$.

- Asked about $\mathrm{HbA}_{1 \mathrm{c}}$ values, some $68 \%$ of all respondents said they knew about this, with a highly significant difference between DMP participants $(80.3 \%)$ and nonparticipants (55.8\%). DMP participants had significantly better mean values $(6.92 \%)$ than non-participants (7.02\%). Among non-DMP participants, there was a sub-group with very poorly controlled diabetes, as indicated by the very similar median $(6.8 \%)$ and the high standard deviation among the non-participants.

- There was a recognisable tendency for non-DMP participants to have a less active approach to coping with diabetes due to knowledge deficits and a generally 'less-preventive' attitude.

- $\quad$ Significantly more non-DMP participants (26.2\%) were dissatisfied with their state of health than participants $(22.7 \%)$. In both groups, one third were satisfied with their condition. Non-DMP participants were significantly more frequently dissatisfied with their life in general than participants $(17.8 \%$ vs. $14.2 \%)$. And participants were more frequently satisfied with their life.

- Some two thirds (63.4\%) of the participants described their state of health as excellent to good (nonparticipants: $60.7 \%), 35.5 \%$ as not so good to poor (non-participants with $38.5 \%$ significantly more frequently). Of DMP participants, $83.8 \%$ had already had diabetes for more than 5 years compared to $84.1 \%$ of non-participants.

- More participants $(12.4 \%)$ assessed the state of their disease as severe (not significant). Significantly more non-participants assessed their disease as less severe to not severe $(34.0 \%$ vs. $28.4 \%)$. The majority of both groups responded with "Not so bad" (Es geht).

- DMP participants had a much more pronounced multimorbidity profile than non-participants. In accordance with their higher morbidity, DMP participants suffered more frequently from painful feet and were more frequently worried about being helpless later and in need of nursing. Nevertheless, more of the DMP participants said that their quality of life had not suffered from diabetes.

\section{Data and methods}

A standardised questionnaire was developed with 51 questions for both DMP participants and non-participants addressing the following topics: health status; life quality ${ }^{1}$; duration of disease; type/place of treatment; comorbidity, disease coping; frequency of visits to doctor, care and therapy objectives; satisfaction with the treatment for diabetes, and the relationship with the doctor and medical personnel; information and participation in training courses; diabetes check-ups, customer satisfaction and knowledge about the DMP. In the second part of the questionnaire, the DMP participants were asked in 13 further questions about their motives for taking part in the programme, changes since they started participating, and their satisfaction with the programme.

\section{Sampling strategy of the insurance customer survey}

In contrast, for example, to another on-going study in which patient samples were drawn from two German federal states on the basis of their visits to general practitioners (Joos et al. 2005, Miksch et al. 2008; Szecsenyi et al. 2008), in our study the basic data of programme participants and non-participants with diabetes

\footnotetext{
${ }^{1}$ Standard instruments for evaluating health-related quality of life, such as SF 12 or SF 36 (Bullinger and Morfeld 2004), are not specifically designed with diabetes in mind. With no validated standards for diabetes-specific instruments (cf. Hirsch 1996, Altenhofen et al. 2005), items were included that were tailored to diabetes type 2 .
} 
were drawn directly and nation-wide from BARMER Health Insurance.

From the total customer register of the health insurance company, the population "all type 2 diabetics" was selected as follows:

BARMER insurance customers aged 45 to 79 years who had been prescribed anti-diabetic drugs both in February 2005 and also in January 2007. A clear allocation to a type of diabetes is often not possible using the data available. However, if there was an indication of diabetes mellitus type 1 , then the individual was not included in the initial population.

We also excluded type 2 diabetics employed by BARMER health insurance company.

The population was determined on 22 February 2007.

Two sub-groups were then formed: DMP participants and non-DMP participants:

Participants were all those who had taken part in the DMP for at least 1 day.

Non-participants had never taken part in the DMP.

From the groups of participants and non-participants, 5,000 diabetics from each were included in a randomised fashion in the sample.

An initial random sample of 1,500 insurance customers was taken from the population of insurance customers who had been DMP participants for less than 1 year (as of 1 May 2007). Since they formed a comparatively small proportion of the overall population, it was expected that the numbers responding would otherwise be too low, and this could possibly have consequences for the measurement of effects thought to be related to the length of participation.

By mid-May, questionnaires had been sent out to 11,500 insurance customers. Responses had to be received by 30 June 2007 to be included in the evaluation.

Responses were received from $38.5 \%$ of the random sample. This is very respectable for a survey that went without follow-up reminders due to time constraints and that was aimed at a group of elderly recipients. After eliminating 80 responses that were incomplete or implausible, we were left with $\mathrm{N}=4,340$ responses for evaluation (DMP participants: 2,158, and Non-participants: 2,182). Because 97 DMP participants did not say how long they had been taking part, only 2,061 participants were considered when analysing the factor programme participation "since about 1 year" or since at least "about 2 years".

It was now important to test how representative the respondents were, and in particular in this case whether respondents with an active attitude to health were overrepresented or not. We found no significant differences for the variables "health status" and "managing with diabetes" between the group of early respondents and those who only returned the questionnaire shortly before the deadline (late respondents). The fact that we found no difference here between early and late respondents argues against the hypothesis that the random sample was specifically selective concerning this factor.

The structural differences in age groups and in average age were small overall-with the exception of the group of non-DMP participants. Due to the given structural differences, the data were weighted for the expected distributions in the population. In other words the net random sample was "standardised" according to age and gender for the relevant distribution relationships in the population. Overall the random sample deviated very little from the structure of the population, and so the weighting factors were very low, apart from for the non-DMP participants. This also applies for the generally small differences between the expected values and the range of the upper and lower confidence intervals. $^{2}$

Since the study was concerned with the investigation of process quality, a range of variables had to be investigated, and there were no specific target variables or even "endpoints". However, it seemed appropriate, in particular with multivariate analyses, to define the measurements of satisfaction (cf. Hall and Dornan 1988; Grogan et al. 2000) as a target variables.

In some items multiple responses were possible, i.e. answers were not mutually exclusive.

In order to examine the statistical importance of bivariate differences between participants and non-participants, the $\mathrm{t}$ test and z-test were used, taking a confidence interval of $95 \%$, i.e. a probability of error of $5 \%(\alpha=0.05)$.

For multivariate analyses, log regressions were carried out. The health satisfaction was chosen as the target variable, expressed as a binary code and examined for the effect with other variables.

\section{Results}

Basic and middle or higher school education in comparison

\section{Social demographic and satisfaction target variables}

As shown in Table 1, significantly more participants had a middle or higher school qualification $(48.8 \%)$ than nonparticipants $(44.6 \%)$. Due to the significant differences in the age structures, for the following bivariate analyses

\footnotetext{
${ }^{2}$ In addition, another type of standardisation was tested according to age and gender. Assuming that non-participants and participants would be similar in terms of both age and gender structure (which is not in fact the real situation, but which leads to full control of these factors), the non-participants were standardised separately to the participants for gender according to age. This led to slightly different values for proportions behind the decimal point without influencing the significance values determined.
} 
Table 1 School education (in \%)

\begin{tabular}{lccr}
\hline & DMP participant $n=2,061$ & Non-DMP participant $n=2,182$ & $\mathrm{p}$ \\
\hline Basic school qualification & 46.4 & 49.7 & 0.0293 \\
Middle or higher school qualifications & 48.8 & 44.6 & 0.0058 \\
No/other school qualification & 4.3 & 4.5 & 0.7490 \\
\hline
\end{tabular}

p: p-value

weighting factors were used to "standardise" data, so that the distribution according to age categories of respondents with middle or higher school education was completely matched to that for respondents with basic schooling.

There were no differences in responses, either with regard to school education or to participating or not participating in the programme, to the question: "How well in general do you cope with your diabetes?" In each case $69 \%$ said that they coped well or very well.

There were clear differences, however, for the target variable of satisfaction (Table 2).

Whereas a higher level of school education was not associated with a difference between participants and nonparticipants for satisfaction with state health or with life in general, in the group with basic schooling the proportion who were dissatisfied was higher than in the group with more school education, and was also higher in comparison with the programme participants.

The situation is different regarding the satisfaction with the diabetes care provided by the doctor: in this case, both educational groups of non-participants were less frequently very satisfied or completely satisfied than the DMP participants. A larger proportion of DMP participants with basic schooling show a higher level of satisfaction than those with higher levels of education (Table 2).

\section{Information and attitudes to the disease}

Unsurprisingly, the self-assessment of the state of knowledge about diabetes was better for higher levels of school education than for basic schooling. The proportion who said they were well informed or very well informed in each case is higher for the programme participants than nonparticipants (basic schooling: $79.1 \%$ vs. $66.0 \%, \mathrm{p}<0.001$; higher school education: $81.7 \%$ vs. $75.0 \%, \mathrm{p}<0.001)$. The same applies for the knowledge about $\mathrm{HbA}_{1 \mathrm{c}}$ values (basic schooling: $79.1 \%$ vs. $54.0 \%, \mathrm{p}<0.001$; higher level of school eduction: 81.6 vs. $59.2, \mathrm{p}<0.001$ ).

About $48 \%$ of the respondents with basic schooling agreed that "You have little or no influence on whether you get diabetes or not" and $44 \%$ of those with higher levels of school education, in each case without a statistically significant difference related to programme participation. A strict diet was experienced as a sacrifice ("I have to go without tasty food")-without significant influence according to programme participation - by fewer respondents with a higher level of schooling and more respondents with only basic schooling, and of these fewer programme participants $(47.3 \%)$ than non-participants $(53.2 ; \mathrm{p}<0.01)$. There is a similar trend for disease prevention-orientation or nonprevention orientation. The statement "It is soon enough to

Table 2 Satisfaction according to school education and DMP participation (in \%)

\begin{tabular}{|c|c|c|c|c|c|c|}
\hline & \multicolumn{3}{|c|}{ Basic schooling } & \multicolumn{3}{|c|}{ Higher level of schooling } \\
\hline & $\mathrm{P} \mathrm{n}=986$ & $\mathrm{NP} n=1,104$ & $\mathrm{p}$ & $\mathrm{P} \mathrm{n}=1,068$ & $\mathrm{NP} n=952$ & $\mathrm{p}$ \\
\hline \multicolumn{7}{|l|}{ Satisfaction with health } \\
\hline Dissatisfied (value 1-3) & 22.1 & 26.9 & 0.0107 & 22.9 & 23.3 & 0.8337 \\
\hline Satisfied (value 5-7) & 32.4 & 32.0 & 0.8451 & 37.5 & 37.4 & 0.9601 \\
\hline \multicolumn{7}{|l|}{ Satisfaction with life } \\
\hline Dissatisfied (value $1-3$ ) & 12.4 & 17.6 & 0.0008 & 15.3 & 15.5 & 0.9045 \\
\hline Satisfied (value 5-7) & 30.4 & 28.7 & 0.3954 & 23.6 & 23.1 & 0.7872 \\
\hline \multicolumn{7}{|c|}{ Satisfaction with diabetes care } \\
\hline Very to completely & 63.2 & 52.0 & 0.0000 & 60.7 & 53.4 & 0.0009 \\
\hline Satisfied & 30.1 & 39.7 & 0.0000 & 33.0 & 38.6 & 0.0089 \\
\hline Less to not at all & 4.8 & 5.3 & 0.6019 & 5.2 & 6.0 & 0.4355 \\
\hline
\end{tabular}

P : Participant

NP: Non-participant

$\mathrm{p}$ : p-value 
change your behaviour when the diabetes causes you real problems" was confirmed by significantly more respondents with basic schooling. In both educational groups, however, fewer DMP participants agreed with the statement (basic schooling: $29.4 \%$ vs. $35.7 \%, \mathrm{p}<0.005$; higher level of schooling: $21.5 \%$ vs. $26.5 \%, \mathrm{p}<0.01$ ).

Treatment, check-ups, therapy goals, training programmes, doctor-patient relationship

More than half of all the respondent diabetics were mainly treated by a general practitioner, and as a trend more of those with only basic schooling. There was a particularly marked difference between the proportions of programme participants and non-participants being treated in a medical office focussing on diabetology. The higher proportion of programme participants in this case only differs slightly with level of schooling (Table 3).

The results are very similar concerning the regular checks of feet, eyes and blood pressure. There is a significant difference with respect to programme participation and hardly any difference relating to level of schooling (feet: basic schooling: $84.9 \%$ vs. $36.1 \%, \mathrm{p}<0.001$, higher level of school education: $82.1 \%$ vs. $63.0 \%, \mathrm{p}<0.001$; eyes: basic schooling: $96.1 \%$ vs. $87.6 \%$, p $<0.001$, higher level of schooling: $95.7 \%$ vs. $83.6 \%, \mathrm{p}<0.001$; blood pressure: basic schooling: $97.0 \%$ vs. $93.9 \%, \mathrm{p}<0.001$, higher level of schooling: $95.8 \%$ vs. $93.8 \%, \mathrm{p}<0.005$ ).

This is continued for the proportion of those who had agreed on therapy goals with their doctor (basic basic schooling: $84.8 \%$ vs. $57.3 \%$, p $<0.001$, higher level of schooling: $85.5 \%$ vs. $74.1 \%, \mathrm{p}<0.001$ ), who had been informed by their doctor about the possibility of taking part in diabetes training programmes (basic schooling: $88.1 \%$ vs. $73.0 \%, \mathrm{p}<0.001$, higher level of schooling: $88.8 \%$ vs. $72.6 \%, \mathrm{p}<0.001$ ), and at a clearly lower level about participation in blood-pressure training (basic schooling: $27.7 \%$ vs. $17.7 \%, \mathrm{p}<0.001$, higher level of schooling: $26.6 \%$ vs. $21.2 \%, \mathrm{p}<0.001)$ as well as for the actual participation in a diabetes training course (basic schooling: $82.2 \%$ vs. $57.3 \%, \mathrm{p}<0.001$, higher level of schooling: $81.4 \%$ vs. $54.9 \%, \mathrm{p}<0.001$ ), and a blood pressure course.

The differences in the relationship with the doctor were on the whole stronger with relationship to DMP participation/non-participation than schooling. The statements "My doctor has informed me in detail about my diabetes", "I have full confidence in my doctor" and "My doctor always takes me seriously" were confirmed with only slight differences according to level of school education by over $90 \%$ of the programme participants and thus more than the non-participants (with the exception that for higher school education it is only significant for "My doctor has informed me in detail about my diabetes"). The responses to "My doctor listens carefully to what I say" differ significantly for basic schooling (participants: $54.6 \%$ vs. $47.6 \%$, p $<0.005$ ), although at a lower level than for the higher level of school education (participants: $60.6 \%$ vs. $56.5 \%$, n.s.).

Concerning doctor's nurses ("Whenever I have questions about diabetes, the doctor's nurse gives me understandable answers", "The nurse has encouraged me to find out more about diabetes"), there are no differences with respect to DMP participation at higher levels of education, but there is a significant difference for basic schooling, and at a higher level of agreement than for the higher level of education, where the nurse obviously plays a less important role in providing information.

"My doctor always involves me in the decisions" (shared decision-making) was confirmed by more participants both among those with basic schooling and (at a slightly higher level) those with higher level school education (basic schooling: $87.8 \%$ vs. $77.5 \%, \mathrm{p}<0.001$, higher level of schooling: $88.8 \%$ vs. $84.5 \%, \mathrm{p}<0.01$ ).

This pattern of a lower influence of education compared with participation in the DMP programme is also repeated for the proportion of smokers (higher for non-participants) and the responses about sporting activity (higher for participants, although with an overall higher level for those with a higher level of education).

Table 3 Main treatment of diabetes in the past 3 months according to level of education and DMP participation (in \%)

\begin{tabular}{|c|c|c|c|c|c|c|}
\hline & \multicolumn{3}{|c|}{ Basic schooling } & \multicolumn{3}{|c|}{ Higher level of schooling } \\
\hline & $\mathrm{P} n=986$ & $\mathrm{NP} n=1,104$ & $\mathrm{p}$ & $\mathrm{P} \mathrm{n}=1,068$ & $\mathrm{NP} n=952$ & $\mathrm{p}$ \\
\hline General practitioner & 53.0 & 63.6 & 0.0000 & 50.7 & 57.8 & 0.0013 \\
\hline Internist, not diabetologist & 15.4 & 20.4 & 0.0028 & 29.9 & 17.4 & 0.0000 \\
\hline GP focussing on diabetology & 27.1 & 13.6 & 0.0000 & 29.9 & 17.4 & 0.0000 \\
\hline Others & 0.2 & 0.7 & 0.0838 & 0.4 & 1.0 & 0.1098 \\
\hline
\end{tabular}

P : Participant

NP: Non-participant

p: p-value 
Table 4 State of health according to educational level and DMP participation (in \%)

\begin{tabular}{|c|c|c|c|c|c|c|}
\hline & \multicolumn{3}{|c|}{ Basic schooling } & \multicolumn{3}{|c|}{ Higher level of schooling } \\
\hline & $\mathrm{P} \mathrm{n}=986$ & $\mathrm{NP} n=1,104$ & $\mathrm{p}$ & $\mathrm{P} n=1,068$ & $\mathrm{NP} n=952$ & $\mathrm{p}$ \\
\hline \multicolumn{7}{|l|}{ Subjective estimate of health status } \\
\hline Excellent to good & 61.0 & 57.9 & 0.1500 & 65.5 & 66.1 & 0.7795 \\
\hline Less good to bad & 37.6 & 41.2 & 0.0931 & 33.1 & 32.9 & 0.9204 \\
\hline \multicolumn{7}{|l|}{ Duration of diabetes } \\
\hline Up to 4 years & 15.2 & 21.9 & 0.0000 & 15.8 & 22.5 & 0.0001 \\
\hline 5 to 10 years & 34.6 & 40.2 & 0.0081 & 37.5 & 39.5 & 0.3577 \\
\hline More than 10 years & 49.1 & 36.8 & 0.0000 & 46.0 & 36.9 & 0.0000 \\
\hline \multicolumn{7}{|l|}{ Severity of the disease } \\
\hline Less severe to not severe & 27.2 & 33.4 & 0.0020 & 30.0 & 36.1 & 0.0037 \\
\hline Not so bad & 57.6 & 53.8 & 0.0081 & 56.0 & 50.8 & 0.0194 \\
\hline Severe to very severe & 12.9 & 10.8 & 0.1390 & 12.5 & 11.5 & 0.4903 \\
\hline \multicolumn{7}{|l|}{ Impediments in every day situations } \\
\hline Severe & 6.4 & 7.3 & 0.4180 & 7.4 & 5.4 & 0.0169 \\
\hline Somewhat & 49.6 & 45.8 & 0.0820 & 47.2 & 43.8 & 0.0017 \\
\hline Not at all & 42.2 & 44.9 & 0.2151 & 44.1 & 49.4 & 0.0169 \\
\hline \multicolumn{7}{|l|}{ Most frequent accompanying diseases } \\
\hline Increased blood pressure & 69.8 & 63.5 & 0.0022 & 65.8 & 59.6 & 0.0169 \\
\hline Joints, back, spinal discs & 61.2 & 54.2 & 0.0012 & 54.1 & 47.2 & 0.0019 \\
\hline Elevated blood lipid values & 37.9 & 34.5 & 0.1075 & 36.7 & 34.1 & 0.2226 \\
\hline Circulation problem affecting the nerves & 20.8 & 16.1 & 0.0058 & 19.8 & 20.4 & 0.7339 \\
\hline Retinopathy & 15.3 & 17.8 & 0.1237 & 15.1 & 12.9 & 0.1529 \\
\hline Allergies/skin diseases & 16.6 & 13.6 & 0.0529 & 20.1 & 13.2 & 0.0000 \\
\hline Cardiovascular system & 12.8 & 9.7 & 0.0529 & 12.9 & 8.4 & 0.0009 \\
\hline Angina pectoris & 12.0 & 10.6 & 0.3126 & 12.0 & 9.6 & 0.0820 \\
\hline Sum of choices & 322.2 & 299.9 & & 314.3 & 277.7 & \\
\hline
\end{tabular}

P : Participant

NP: Non-participant

p: p-value

\section{State of health, morbidity and mental well-being}

Finally, a comparison is made both in terms of schooling and programme participation of states of health, morbidity and mental well-being, where the influences of social status or of education in generael are well known.

There is indeed a markedly higher proportion with only basic schooling who say that their state of health is less good or bad, also with a higher proportion for non-DMP participants than participants, although this is not statistically significant (Table 4).

This corresponds to the fact that a duration of diabetes above 10 years is more frequent among those with basic schooling, although the difference among both educational groups is greater for those who participate in the programme. There is no statistically significant difference for the severity of the disease, although "less severe to not bad" is less frequent for those with only basic education and in each group less frequent for the DMP participants. This higher morbidity on the one hand related to a lower level of education and on the other hand programme participation is also shown overall for the "Extent to which diabetes hinders carrying out daily tasks, e.g. at home or at work". The same applies for the frequency of accompanying diseases or multi-morbidity (Table 4), and for mental well-being, which is not shown here.

\section{Analyses of the DMP participants}

\section{Reasons for signing on to the DMP programme}

The main reasons given for signing on to the DMP programme were the expectation of closer cooperation with the doctor and more intensive treatment. Three-quarters of the DMP participants believe that they will avoid repeat investigations, or they hope to be handled better by BARMER. About two-thirds of the DMP participants who replied hoped for more concessions; the same number expected more information. Free advice on diet and the possibility to take part in courses were given with about equal frequencies as reasons for signing on to the programme. The main reasons for deciding to participate were the quality of care and the doctor-patient relationship. And, again, few respondents had a monetary motivation to 
take part, although this is frequently mooted as a control instrument in health policy discussions. The offer of a bonus of 40 euros only ranks fifth among the reasons to participate in the DMP programme.

In Table 5, the reasons are ranked and differentiated according to level of school education, showing very few differences in the actual rankings. However, with the exception of better care by the doctor and the avoidance of repeat investigations, there was a tendency for a higher proportion of participants with basic schooling to choose a given reason. This applies in particular for the reasons outside the top five, which all relate to the services expected from the health insurer. Here it seemed that participants with higher levels of schooling felt less need for improvements.

\section{Changes since participating in the DMP}

Almost half the DMP participants said that their state of health had improved since they started participating. Some $45 \%$ saw no improvements in their state of health, and only $4 \%$ said things had gotten worse (Elkeles et al. 2008). There was no difference in the changes in state of health between participants with basic or higher levels of school education.

Of 20 questions about changes or improvements due to the participation in the DMP, 13 were answered positively by a majority of participants (responses "correct" or "completely correct"). Overall, the top place was paying more attention to check-ups and to values and doctor's appointments. Almost three-quarters agreed that their diabetes was controlled better. Almost half said that their blood pressure and blood lipid levels had fallen.

Differentiated in terms of schooling, once again for similar rankings a majority of statements from the participants with basic schooling were agreed with significantly more frequently (Table 6). Of these, only one is a negative evaluation ("Don't see any benefits"; $28.2 \%$ vs. $23.9 \%$ ); all other significant differences relate to positive statements. According to their own statements, the participants with only basic schooling benefited more from the DMP than participants with a higher level of schooling (Table 7).

For more than $59 \%$ of the participants, the medication was not changed. More than a quarter of the participants said that the doctor advised them above all to start a diet. This was stated by significantly more participants with basic schooling (30.1\%) than participants with higher levels of schooling $(23.0 \%)$.

For $54.8 \%$ of the participants, the number of visits to the doctor was unchanged, $36.7 \%$ paid more visits and only $5.6 \%$ saw their doctor less frequently. There was no difference here according to level of school education.

Nearly two thirds $(61.3 \%)$ of participants thought that their doctor took more time for them. Significantly more of the participants with basic schooling $(63.0 \%)$ than of participants with a higher level of schooling (57.6\%) said that the doctor had had more time for them since they began participating in the programme.

\section{Comments about the programme, satisfaction, willingness to participate again and recommendations to others}

Of the DMP participants, some $51 \%$ said they had heard about the programme from BARMER, and $76 \%$ said their doctor had told them about it. Significantly more participants with only basic schooling $(45.8 \%)$ were told about the programme by their general practitioner than participants with higher levels of schooling (41.0\%).

Nearly half $(44.5 \%)$ of the participants were completely or very satisfied, $46.5 \%$ said they were satisfied and only $6.2 \%$ were less satisfied or unsatisfied. A fifth $(20.4 \%)$ of those with basic schooling were completely satisfied compared with $14.3 \%$ of those with higher levels of schooling (significant).

Table 5 Reasons for signing up to the DMP according to level of schooling (in \%)

\begin{tabular}{|c|c|c|c|}
\hline & Basic schooling $n=986$ & Higher level of schooling $n=1,068$ & $\mathrm{p}$ \\
\hline More intensive treatment/checks & 90.7 & 89.4 & 0.3422 \\
\hline Closer cooperation doctor/patient & 91.5 & 88.8 & 0.0386 \\
\hline Better care by doctor & 86.0 & 86.7 & 0.3473 \\
\hline Avoiding repeat investigations & 77.8 & 79.5 & 0.3473 \\
\hline Bonus & 73.8 & 69.6 & 0.0317 \\
\hline Better service by BARMER & 74.3 & 66.6 & 0.0001 \\
\hline More concessions from BARMER & 72.0 & 67.4 & 0.0057 \\
\hline Possibility to take courses & 70.1 & 68.4 & 0.3954 \\
\hline Diet advice & 60.0 & 56.0 & 0.0630 \\
\hline More information from BARMER & 63.3 & 57.8 & 0.0105 \\
\hline BARMER health telephone & 29.1 & 20.4 & 0.0000 \\
\hline
\end{tabular}

p: p-value 
Table 6 Changes since participation in the DMP according to schooling (in \%)

\begin{tabular}{lll}
\hline & Basic schooling $\mathrm{n}=986$ & Higher level of schooling $\mathrm{n}=1,068$ \\
\hline My diabetes is controlled better & 74.7 & 71.5 \\
Treatment is more intensive & 75.4 & 74.4 \\
Better guidance for self-control & 75.4 & 69.2 \\
My doctor takes more time & 72.5 & 66.9 \\
Doctor pays more attention to appointments & 81.5 & 76.0 \\
I pay more attention to values and appointments & 82.9 & 77.3 \\
Pay more attention to the illness & 72.6 & 65.5 \\
Had hoped for more & 32.2 & 34.0 \\
Don't let things drag so easily & 64.9 & 58.4 \\
Less afraid of later consequences & 58.7 & 49.1 \\
Know that check-ups are important & 88.8 & 83.3 \\
Check values myself & 75.7 & 66.2 \\
Pay attention to more movement & 71.8 & 67.2 \\
Have changed my diet & 65.1 & 61.5 \\
Don't smoke any more & 28.8 & 27.4 \\
Everything is a lot of trouble & 17.8 & 14.8 \\
Living with diabetes not really better & 41.2 & 39.9 \\
My blood pressure has fallen markedly & 49.5 & 40.7 \\
My blood lipid levels have sunk markedly & 48.4 & 44.5 \\
Don't see any benefits & 28.2 & 23.9 \\
\hline
\end{tabular}

p: p-value

Table 7 Multivariate model: Health satisfaction

\begin{tabular}{|c|c|c|c|c|c|}
\hline & n 2,321 & Odds ratio ${ }^{1}$ & $95 \%$ lower confidence interval & $95 \%$ upper confidence interval & $\mathrm{p}$ \\
\hline \multicolumn{6}{|l|}{ DMP } \\
\hline Non-participant in DMP & 1,191 & 0.76 & 0.63 & 0.91 & 0.0027 \\
\hline Participant in DMP & 1,130 & 1 & & & \\
\hline \multicolumn{6}{|l|}{ Sex } \\
\hline Male & 1,314 & 1 & & & \\
\hline Female & 1,007 & 0.64 & 0.54 & 0.77 & 0.0000 \\
\hline \multicolumn{6}{|l|}{ School education } \\
\hline Basic schooling & 1,147 & 0.83 & 0.69 & 0.99 & 0.0368 \\
\hline Higher schooling & 1,881 & 1 & & & \\
\hline \multicolumn{6}{|l|}{ Duration of diabetes disease } \\
\hline Up to 10 years & 1,383 & 1.08 & 0.89 & 1.30 & 0.4453 \\
\hline More than 10 years & 938 & 1 & & & \\
\hline \multicolumn{6}{|l|}{ Age } \\
\hline $45-59$ years & 410 & 0.72 & 0.56 & 0.93 & 0.0118 \\
\hline $60-69$ years & 923 & 1.15 & 0.94 & 1.40 & 0.1673 \\
\hline $70-79$ years & 510 & 1 & & & \\
\hline \multicolumn{6}{|l|}{ Type of care } \\
\hline Diabetology centre & 510 & 0.81 & 0.65 & 1.01 & 0.0649 \\
\hline Internist & 431 & 0.91 & 0.72 & 1.16 & 0.4618 \\
\hline General practitioner & 1,380 & 1 & & & \\
\hline \multicolumn{6}{|l|}{ Severity of diabetes } \\
\hline Less/not severe & 855 & 7.59 & 5.57 & 10.33 & 0.0000 \\
\hline Not so bad & 1,157 & 2.78 & 2.10 & 3.68 & 0.0000 \\
\hline Severe to very severe & 460 & 1 & & & \\
\hline
\end{tabular}

${ }^{1}$ Results for health satisfaction, value $5-7$ on a 7 -point scale $(1=$ very unsatisfied, $7=$ very satisfied)

Reference: satisfied, less satisfied and not satisfied, value $1-3$, with the health

p: p-value 
Given this high level of satisfaction with the programme, it is not surprising that $94.0 \%$ of participants said that they would choose to take part in the programme again, and a similar proportion would recommend it to others. The willingness to recommend it to friends and relations with diabetes was once again (significantly) more prevalent among participants with basic schooling (92.6\%) than among participants with higher levels of schooling (89.8\%).

\section{Multivariate analyses}

For all the respondents with diabetes mellitus type 2, health satisfaction is a key indicator for health and for successful care ("How satisfied are you with your health?", Table 2).

For multivariate analysis, the three highest categories of health satisfaction (value 5-7 of a 7-point scale) formed one group, and the lowest three categories (values 1-3) were also combined in a reference group. The influence on these binary satisfaction values for health satisfaction was measured simultaneously with logistic regression with the factors DMP participation, age (classified), school education (basic or higher), duration of the diabetes disease (classified), type of doctor and the perceived severity of the disease. The group of those less or not satisfied with their health was chosen as a reference in the model.

Overall there were 1,043 more to completely satisfied respondents and 1,486 less or not satisfied ones, with 2,321 of all respondents in the model calculation. The difference is due to value $4(n=1,689)$ and to missing responses for the various model variables. The resolution between the groups in the model is significant (above 99\%). Model fit for the intercept only is $-2 \log$-likelihood $1,264.8$ and for the final model -2 log-likelihood 971.5.

The direction and strength of the individual parameters were expressed by the odds ratios. Respondents not participating in the Disease Management Programme had a 34\% lower chance of being more or completely satisfied with their health compared with DMP participants.

A further statistical significance in this model is that women had a $36 \%$ lower chance than men of being more or completely satisfied with their health.

The duration of the diabetes disease does not have an influence in this model on health satisfaction. No influence on health satisfaction is also related to the organisational nature of the medical care provided and with age. However, the severity of the disease also has a high influence on the level of health satisfaction in the model. Those with not severe or less severe diabetes have a seven times higher chance of being more or completely satisfied with their health than those with severe disease.

Also there is a slight significant influence on the health satisfaction attributable to schooling, because the bivariate influence remained statistically in the multivariate model.

\section{Discussion}

Initially, we asked whether there were indications that selfselection and social selection processes could mean that health programmes preferentially recruit from social groups with comparatively less need. The finding that significantly more DMP participants $(49 \%)$ have a higher level of school education than non-participants $(45 \%)$ could be taken as evidence for such a tendency, from a socio-epidemiological viewpoint.

The results also show that a lower level of education is related to an increased morbidity, a poorer level of information and also a less well-developed 'preventive attitude' towards the diabetes. However, in comparison with the other differences analysed between the DMP participants and non-participants, these factors are less pronounced and less influential. Thus, for a series of comparisons the difference between programme participants and non-participants was greater than that between the different levels of school education.

Indications about the strength of the influence of the chosen target variable of satisfaction with the state of health were provided by multivariate analysis. Plausibly, for this target variable the influence of the severity of the disease was greatest, while the duration of the disease, the type of doctor and also age (at least for those in their 60s) played no role. The influence of gender was also greater in this model than in another model, not presented here, with the target variable of satisfaction with the diabetes care provided by the doctor. At the same time it should be noted that the multivariate analysis showed that an independent, positive effect on the satisfaction with the state of health is exerted both by programme participation and also by the higher level of schooling, with the effect due to programme participation being stronger. To this extent it confirms the positive results for the effect of programme participation from the general analysis (Elkeles et al. 2008) and reduces the fears from the preceding Neubrandenburg Regional Survey (Elkeles et al. 2007) that there were selection effects to the disadvantage of those with lower social status.

As in the general analysis (Elkeles et al. 2008) and in the previous Neubrandenburg Regional Survey (Elkeles et al. 2007), the main reasons for deciding to participate were the quality of care and the doctor-patient relationship, with only few differences between basic and higher school education level.

More social influence could be found concerning the differences in treatment provided within the programme. Patients obviously appreciate that the medical personnel and the health insurance company are paying increased attention to their disease, and as shown by various differences in the responses given by the programme partic- 
ipants, this applies to a greater extent for participants with a lower level of schooling. Although this group is significantly underrepresented among the participants, a larger proportion of them reported that they were benefiting from the Disease Management Programme.

Although the results of the investigation presented here, in particular after the multivariate analyses, are more unambiguous throughout than we actually expected, it should be noted that some of the results for the nonparticipants (e.g. frequency of check-ups) were also very good. Although in Germany there have been appreciable deviations by international standards at least until fairly recently from health-care policy targets, it is possible that we are also gradually beginning to see the effects of regional programmes from the period before the DMP was started up (Lippmann-Grob et al. 2006; Blumenstock et al. 2006; Eichenlaub and Steiner 2005; Schunk et al. 2007; Rothe et al. 2008) or that there has been a general paradigm shift in the care for diabetics in Germany.

According to the results of our study of 45 to 79 year olds, it seems that at least for customers of BARMER health insurance there has been a marked (additional) positive effect as a result of the DMP for diabetes mellitus type 2 , although it must be added that a single survey of this sort does not tell us anything about the extent to which foreign experience with the effectiveness or efficiency of DMPs (cf. Sidorov et al. 2002) can be transferred to Germany, nor can a survey of insurance customers provide insights regarding cost-effectiveness, at least not on the basis of the evaluation presented here (however, see Elkeles et al. 2008 with evaluations of subjective statements about the use of doctors' services). However, BARMER does have positive results on the basis of comparative analyses of the records of patients with diabetes mellitus who do or do not participate in the diabetes mellitus type 2 DMP (Ullrich et al. 2007; Graf et al. 2008).

\section{Conclusion}

Surveys of health insurance customers can provide valuable information about the opinions of the patients themselves and allow the investigation of social influences. In order to reduce the limitations on the potential of customer surveys on the one hand and of quality assurance studies on the other, we propose again (cf. Elkeles et al. 2007) that quality assurance studies should be carried out in order to validate surveys addressing participants in DMPs, and conversely surveys of DMP participants should be conducted to validate quality assurance findings.

Conflict of interest The authors disclose any relevant associations that might pose a conflict of interest.

\section{References}

Altenhofen L, Hagen B, Hass W (2005) Aspekte der Lebensqualität älterer Typ 2-Diabetiker-Ergebnisse aus einer Patientenbefragung unter Teilnehmern der Diabetes-Strukturvereinbarungen Nordrhein. In: Badura B, Iseringhausen $\mathrm{O}$ (eds) Wege aus der Krise der Versorgungsorganisation. Beiträge aus der Versorgungsforschung. Hans Huber Verlag, Bern, pp 238-254

Altenhofen L, Hagen B, Hass W (2006) DMP Diabetes mellitus Typ 2-Was zeigen die bisherigen Ergebnisse aus Nordrhein? http:// www.zi-berlin.de/dmp/downloads.php (08.03.2008)

Blumenstock G, Matziou P, Weigel I, Selbmann H-K (2006) Beschreibung der Diabetiker-Versorgung aus PatientensichtBefragungsergebnisse im Diabetes-Modellvorhaben Südwürttemberg. Diabetes und Stoffwechsel 1(3):173-180

Bullinger M, Morfeld M (2004) Der Health Survey SF-36/SF-12: Darstellung und aktuelle Entwicklungen. In: Maurischat C, Morfeld M, Kohlmann T, Bullinger M, eds Lebensqualität: Nützlichkeit und Psychometrie des Health Survey SF-36/SF-12 in der medizinischen Rehabilitation. Pabst, Lengerich, pp 15 27

Busse R (2004) Disease Management programs in Germany's statutory health insurance system. Health Aff 23(3):56-67

Dunkelberg S, Zingel D, Noack A, van den BH, Kaduszkiewitz H (2006) Welche Patienten werden (nicht) in das DMP Diabetes eingeschlossen? Gesundheitswesen 68:289-293

Eichenlaub A, Steiner M (2005) Verbesserte Diabetikerversorgung in Sachsen-Anhalt. Ergebnisse der Evaluation des Diabetes Modellprojektes (1. Quartal 2001 bis 4. Quartal 2002). Zeitschrift für ärztliche Fortbildung und Qualitätssicherung im Gesundheitswesen 99(3):191-195

Eller M, Satzinger W, Holle R, Meisinger C, Thorand B (2005) DiseaseManagement-Programme in Deutschland: Erste Reaktionen der Diabetiker. Gesundheitswesen 67, Special Issue 1:144-149

Elkeles T, Heinze S, Eifel R (2007) Healthcare by a DMP for Diabetes mellitus Type 2-Results of a survey of participating insurance customers of a health insurance company in Germany. J Publ Health 15(6):473-80

Elkeles T, Kirschner W, Graf C, Kellermann-Mühlhoff P (2008) Versorgungsunterschiede zwischen DMP und Nicht-DMP aus Sicht der Versicherten. Ergebnisse einer vergleichenden Versichertenbefragung von Typ 2-Diabetikern der BARMER. Gesundheits- und Sozialpolitik 62(1):10-18

Faller H (2006) Patientenorientierung im Gesundheitswesen: Arztpatient-beziehung, shared decision making, empowerment. In: Pawils S, Koch U (eds) Psychosoziale Versorgung in der Medizin. Entwicklungstendenzen und Ergebnisse der Versorgungsforschung. Schattauer, Stuttgart, pp 74-84

Gerlach FM, Beyer M, Szecsenyi J, Raspe H (2003) Evaluation von Disease-Management-Programmen-Aktuelle Defizite, Anforderungen, Methoden. Zeitschrift für ärztliche Fortbildung und Qualitätssicherung im Gesundheitswesen 97:495-501

Graf C (2006) Disease Management Programme und Integrierte Versorgung. Gesundheits- und Sozialpolitik 60(5-6):42-52

Graf C, Ullrich W, Marschall U (2008) Nutzenbewertung der DMP Diabetes mellitus? Neue Erkenntnisse aus dem Vergleich von DMP-Teilnehmern und Nichtteilnehmern anhand von GKVRoutinedaten und einer Patientenbefragung. Gesundheits- und Sozialpolitik 62(1):19-30

Grogan S, Conner M, Norman P, Willits D, Porter I (2000) Validation of a questionnaire measuring patient satisfaction with general practitioner services. Qual Health Care 9:210-215

Hall JA, Dornan MC (1988) Meta-analysis of satisfaction with medical care: description of research domain and analysis of overall satisfaction levels. Soc Sci Med 27(6):637-644 
Häussler B, Wille E, Wasem J, Storz P (2005) Diabetiker im Disease Management. Erste Erkenntnisse über die Wirkung der Disease Management Programme in der gesetzlichen Krankenversicherung. Gesundheits- und Sozialpolitik 59(9-10):23-33

Hirsch A (1996) Diabetes und Lebensqualität. In: Petermann F (ed) Lebensqualität und chronische Krankheit. Dustri, München, pp $185-222$

Joos S, Rosemann T, Heiderhoff M, Wensing M, Ludt S, Gensichen J, Kaufmann-Kolle P, Szecsenyi J (2005) ELSID-Diabetes studyevaluation of a large scale implementation of disease management programmes for patients with type 2 diabetes. Rationale, design and conduct-a study protocol. BMC Public Health 5:99

Knight K, Badamgarav E, Henning JM, Hasselblad V, Gano AD Jr, Ofman JJ, Weingarten SR (2005) A systematic review of diabetes disease management programs. Am J Manag Care 11(4):242-250

Lippmann-Grob B, Bierwirth RA, Kron P, Leinhos B, Funke K, Huptas M, Grüneberg M, Weich KW, Münscher C, Potthoff F (2003) Patientenklassifikation und Risikoprofilanalysen bei Typ2-Diabetikern in der Schwerpunktpraxis. Ergebnisse der TEMPO-Studie. Deut Med Wochenschr 129:75-81

Lippmann-Grob B, Hillenbrand H, Kolonko B, Vogelmann M (2006) Diabetikerversorgung in Baden-Württemberg. Messung der Versorgungsqualität mittels Patientenbefragung im Rahmen des Projektes "Regionale Versorgungsqualität der Arbeitsgemeinschaft Diabetologie Baden-Württemberg (ADBW)". Diabetes, Stoffwechsel und Herz 15(1):21-28

Miksch A, Hermann K, Trieschmann J, Roelz A, Heiderhoff M, Laux G, Rosemann T, Szeczenyi J (2008) Gender-specific differences in quality of life of patients with type 2 diabetes with or without participating in DMP. Gesundheitswesen 70:250-255

Morfeld M, Koch U (2005) Ansprüche an die Evaluation komplexer Gesundheitsprogramme-Disease-Management-Programme in Deutschland. Zeitschrift für ärztliche Fortbildung und Qualitätssicherung im Gesundheitswesen 99(3):179-184

Robinson R, Steiner A (1998) Managed health care: US evidence and lessons for the National Health Service. Open University Press, Buckingham

Rothe U, Müller G, Schwartz PE, Seifert M, Kunath H, Koch R, Bergmann S, Julius U, Bornstein SR, Hanefeld M, Schulze J (2008) Evaluation of a diabetes management system based on practice guidelines, integrated care and continuous quality management in a federal state of germany: a population-based approach to health care research. Diabetes Care 31:863-868

Saltman R, Otter Cv (1995) Implementing planned markets in health care. Open University Press, Buckingham
Selby JV, Scanlon D, Lafata JE, Villagra V, Beich J, Salber PR (2003) Determining the value of disease management programs. Joint Commission journal on quality and safety 29(9):491-499

Scheibler F, Pfaff H eds (2004) Shared decision-making: von der Compliance zur partnerschaftlichen Entscheidungsfindung. Hans Huber Verlag, Bern [et al.]

Sidorov J, Shull R, Tomcavage J, Girolami S, Lawton N, Harris R (2002) Does Diabetes Disease Management save money and improve outcomes? Diabetes Care 25 4:684-689

Szecsenyi J, Rosemann T, Joos S, Klimm FP, Miksch A (2008) German diabetes disease management programmes are appropriate to restructure care according to the Chronic Care Model. An evaluation with the Patient Assessment of Chronic Illness Care (PACIC-5A) instrument. Diabetes Care 31(6):1150-1154

Schunk M, Schweikert B, Gapp O, Reitmeir P, Meisinger C, Mielck A, Holle R (2007) Zeitliche Veränderungen in Versorgung und Krankheitsmanagement von Diabetes Typ 2 - Patienten zwischen 1997 und 2005. Analyse zweier bevölkerungsbasierter Studien (KORA Augsburg). In: Wichmann H-E, Nowak D, Zapf A, eds. Kongress Medizin und Gesellschaft 2007, Augsburg 17.-21.September 2007, Abstractband. Rheinware Verlag, Mönchengladbach, p 322

SVR (Sachverständigenrat zur Begutachtung der Entwicklung im Gesundheitswesen) Kooperation und Verantwortung. Voraussetzungen einer zielorientierten Gesundheitsversorgung. Gutachten 2007

Todd WE, Nash D (eds) (1997) Disease management: a systems approach to improving patient outcomes. American Hospital Pub, Chicago

Ullrich W, Marschall U, Graf C (2007) Versorgungsmerkmale des Diabetes mellitus in Disease-Management-Programmen. Ein Vergleich von in die DMP eingeschriebenen und nichteingeschriebenen Versicherten mit Diabetes. Diabetes, Stoffwechsel und Herz 16:407-414

Veeder NW, Peebles-Wilkins W (2001) Managed care services: policy, programs, and research. Oxford University Press, New York

Wegscheider K, Romes C, Gawlik C (2006) Evaluation von Disease Management Programmen in Deutschland. In: Göpffarth D, Greß S, Jacobs K, Wasem J (eds) 10 Jahre Kassenwahlfreiheit. Jahrbuch Risikostrukturausgleich 2006. Asgard, St. Augustin, pp 261-278

Weingarten SR, Henning JM, Badamgarav E, Knight K, Hasselblad V, Gano A Jr, Ofman JJ (2002) Interventions used in disease management programmes for patients with chronic illness which one works? Meta-analysis of published reports. Br Med J 325(26):925-927 October 